\title{
Proyecto IDDEA: realización de una instalación artística en Educación Infantil
}

\author{
Rodríguez Cano Sonia ${ }^{a}$, Delgado Benito Vanesa ${ }^{b}$, Ausín Villaverde Vanesa
}

${ }^{a}$ Universidad de Burgos, srcano@ubu.es, ${ }^{b}$ Universidad de Burgos, vdelgado@ubu.es, ${ }^{c}$ Universidad de Burgos, vausin@ubu.es

\begin{abstract}
Resumen
El proyecto IDDEA (Investigación del Desarrollo Didáctico de la Expresión y el Arte) es una iniciativa educativa que nace desde Asire Educación, una Asociación que apuesta por una educación integral potenciando, entre otros aspectos, el desarrollo intelectual, personal y social tanto de los alumnos como de los profesionales de la educación.

Tomando como referencia la pedagogía artística, IDDEA surge de la necesidad de atender temas sociales y planteamientos escolares desde una perspectiva artística a través de la cual la obra de arte y el artista se convierten en foco didáctico mediante el que se trabajan los diferentes contenidos temáticos.
\end{abstract}

Palabras clave: pedagogía artistica infantil, creatividad

\section{Introducción}

Durante el curso 2018/2019 se ha llevado a cabo una intervención con alumnos de Educación infantil con los que se ha realizado una instalación artística a partir de la obra pictórica "El Jardín” de Joan Miró.

La instalación artística es un género de arte contemporáneo que surge como un movimiento artístico donde la idea de la obra prevalece sobre sus aspectos formales y se caracteriza por poder presentarse en cualquier espacio.

Esta intervención se ha desarrollado desde la pedagogía artística, concibiendo al arte como un instrumento de trabajo pedagógico versátil y reflexivo que ayuda al alumno a proyectar ideas y también a recibirlas y recrearse en las de otros. En definitiva, constituye un diálogo visual en el que se establecen interrelaciones intencionales y no intencionales que enriquecen el proceso didáctico y facilitan los aprendizajes. 
Ligado a la pedagogía artística, encontramos la metodología "Art thinking", la cual se fundamenta en los descubrimientos de la neuroeducación y se inspira en los procesos de creación de arte siendo su principal hallazgo que para que se produzca el aprendizaje es necesario encender una emoción y/o despertar la curiosidad del alumno.

\section{Fundamentación}

Uno de los pilares fundamentales para la Educación Infantil desde el siglo XIX, es el juego. Fröebel, ya idea un centro infantil cuyo desarrollo parte de actividades espontáneas y el juego se convierte en el proceso esencial y principal para desarrollar los aprendizajes de una forma natural.

También Piaget desde su teoría evolucionista, desarrolla este principio:

“...se encuentran tres grandes tipos de estructuras que caracterizan los juegos infantiles y dominan la clasificación: el ejercicio, el símbolo y la regla; los juegos de "construcción" constituyen la transición entre los tres y las conductas adaptadas...ejercicio, símbolo y regla parecen ser los tres estadios sucesivos característicos de las grandes clases de juegos, desde el punto de vista de sus estructuras mentales." (Piaget, 1982, p.149).

IDDEA parte como proyecto de una concepción lúdica del aprendizaje y mediante un proceso artístico, en cuyo desarrollo quedan integrados los aprendizajes de forma globalizada. Para Alonso-Geta (2007) el juego, construye la personalidad, el entendimiento y los estilos cognitivos, los sentimientos y emociones, valores intelectuales y también el autocontrol, autonomía y la autoestima del niño. El objetivo principal del proyecto es desarrollar la creatividad partiendo de objetivos didácticos y mediante procesos artísticos.

El arte, la expresión artística original, ha sido planteado en este proyecto como un juego en el que no hay una única producción válida sino que se pueden y deben explorar y utilizar diferentes materiales.

Siguiendo a Delgado Linares (2011), para el desarrollo de las sesiones del proyecto se han contado con las siguientes etapas o características para desarrollar la intervención educativa:

- Diagnóstico previo: Mediante el contacto con el profesorado del centro, para conocer sus necesidades y encajar la actividad dentro de la programación habitual.

- Objetivos didácticos: Para esta instalación artística se desarrollaron objetivos didácticos entorno a la obra y características de esta del artista Joan Miró. Siempre desde una metodología activa y lúdica.

- Conocer hitos relevantes de la vida del artista.

- Desarrollar conocimientos sobre la obra: formas y colores utilizados 
- Conocer y realizar una "Obra Mironiana”

- $\quad$ Plasmar con originalidad sus ideas

- Generar un clima creativo y artístico

- Desarrollar pautas estéticas

- Justificación de la actividad: La actividad se justifica desde el enfoque globalizado, como nexo de unión entre las diferentes áreas de educación infantil y como punto de reflexión sobre los contenidos programados para el proyecto.

- $\quad$ Planificación adecuada: Se han realizado tres sesiones (una por semana) lo cual daba continuidad a la instalación y permitía reforzar los aprendizajes.

- $\quad$ Evaluación de la actividad: La actividad ha sido evaluada observacionalmente y mediante unos sencillos cuestionarios. Se ha realizado tanto a los niños como a las profesoras del centro.

Otro de los principios fundamental de la educación infantil es la globalización, el cual, según Suarez, supone entender que el aprendizaje es un proceso unitario y global, a la vez que desarrollar un conjunto de habilidades y capacidades (cognitivas, afectivas y motrices) y que permitan significación y relación Suarez (2011).

La globalización forma parte del desarrollo de la idea de educación integral, teoría que se mantiene en las más actuales corrientes pedagógicas, el arte ha sido en algunas metodologías el elemento aglutinador de las áreas, contenidos y objetivos en educación infantil, como en la pedagogía waldorff o en Reggio Emilia

Esta intervención queda enmarcada dentro de la clasificación que realiza Medina, aglutinando La globalización como estructura psicológica de aprendizaje que está centrada en el alumno: los alumnos observan, manipulan, clasifican y establecen relaciones de los procesos de E-A.

Para materializarlo en el aula de educación infantil, como estructura psicológica y siguiendo los pasos de Medina, se han realizado las actividades de la intervención siguiendo estas pautas globalizadoras:

a) No fragmentar los contenidos.

b) Inclusión de contenidos de diversas áreas y sus relaciones entre ellas.

c) Partir de los conocimientos previos y significativos

d) Seleccionar una temática adaptada a cada grupo y contexto. 


\section{Desarrollo de la intervención:}

Para esta intervención del proyecto IDDEA se distribuyeron las actividades en tres días de 9.00 a 12.00 adaptándonos al horario de clases habitual y respetando la media hora de recreo de cada uno de los grupos.

Se realizó la intervención con tres clases de educación infantil de un ceip público de la zona centro de Burgos. Un total de 60 niños de edades comprendidas entre los tres y los cinco años.

\subsection{Sesiones}

Las sesiones se dividieron en tres días, en horario de $9 \mathrm{~h}$ a $12 \mathrm{~h}$ en las que se fueron alternando actividades en gran grupo: vídeos, cuentos o pequeñas dramatizaciones sobre los contenidos, con actividades en grupos pequeños: manipulativas y cooperativas e individuales: reflexivas y creadoras.

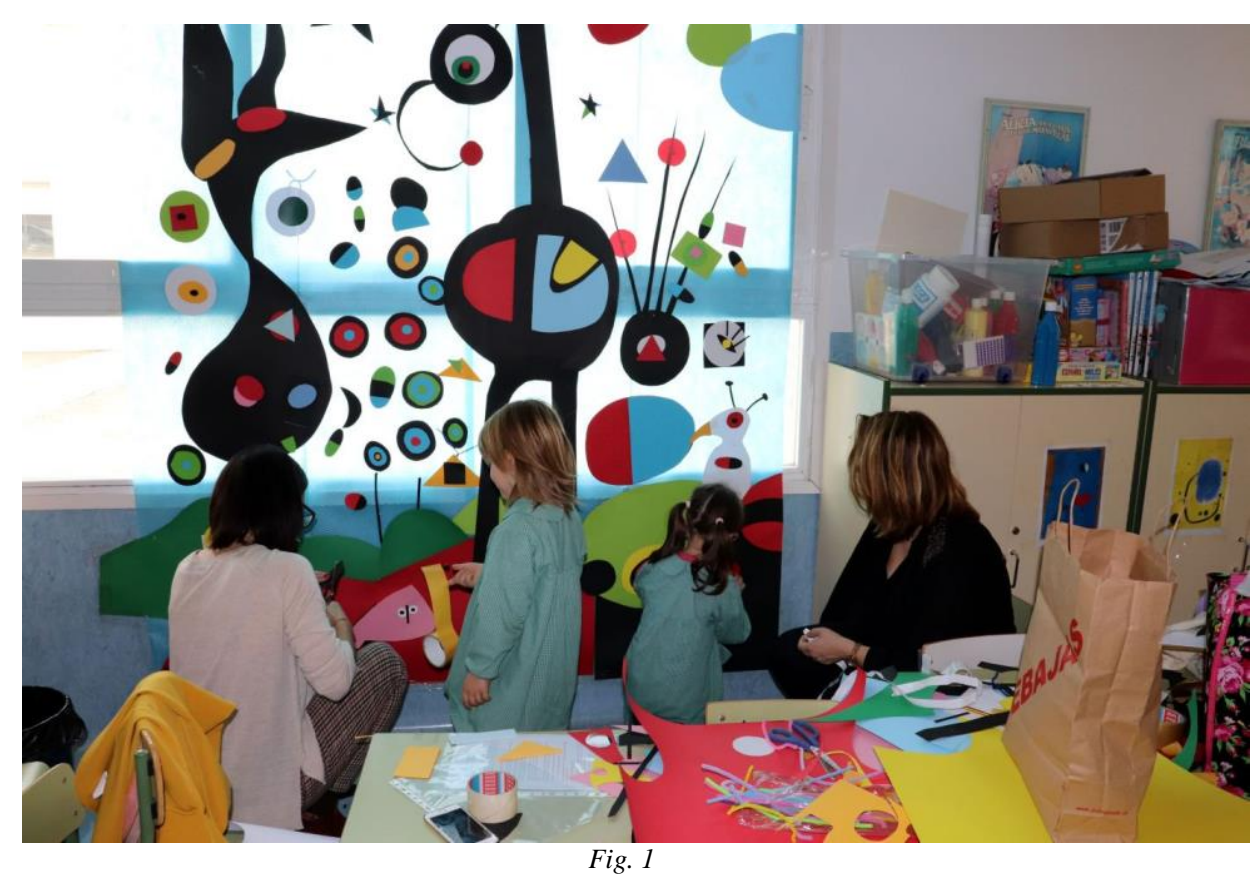

Fuente: Elaboración Propia 
Durante las intervenciones el aula se convierte en un espacio abierto, se utilizan los pasillos, los patios (si existe esta posibilidad).

Los materiales son accesibles al alumno y se incluyen materiales de uso no habitual en el colegio para despertar la curiosidad y fomentar la manipulación y el juego con el material. El ambiente de trabajo es flexible y poco directiva, pues son numerosos los autores que consideran que el ambiente flexible favorece la fluidez, flexibilidad y originalidad (Espríu, 2005).

\subsection{Evaluación}

En cuanto a la evaluación, se desarrolló de forma observacional sin poner ningún énfasis en el resultado final sino en el proceso de creación y en la evolución del niño dentro del proyecto. En esta parte de la evaluación se pudo comprobar como los niños van interactuando entre ellos y disfrutando del proceso de aprendizaje y creación que se les propone, cada día son más autónomos en el uso de los materiales y más arriesgados en sus propuestas.

Para la evaluación de esta intervención como eje globalizador de contenidos de diferentes áreas, se pasó un breve cuestionario de conocimientos de diferentes áreas de educación infantil, evaluando contenidos legislados en la L.O.M.C.E., actual Ley Orgánica Española, aprobada en 2013.

Las áreas de conocimiento del Segundo Ciclo de Educación Infantil son las siguientes:

- $\quad$ Conocimiento de sí mismo y autonomía personal.

- $\quad$ Conocimiento del entorno.

- $\quad$ Lenguajes: comunicación y representación.

Estas áreas son definidas por el MECD como: “Ámbitos de actuación, como espacios de aprendizajes de todo orden: de actitudes, procedimientos y conceptos que contribuirán al desarrollo de niñas y niños y facilitarán su interpretación del mundo, otorgándole significado y promoviendo su participación activa en él” (MECD, 2013).

La interrelación de las áreas de educación infantil legisladas y el desarrollo de la intervención ha sido realizado a través de los objetivos y contenidos interdisciplinares, flexibles y abiertos. 

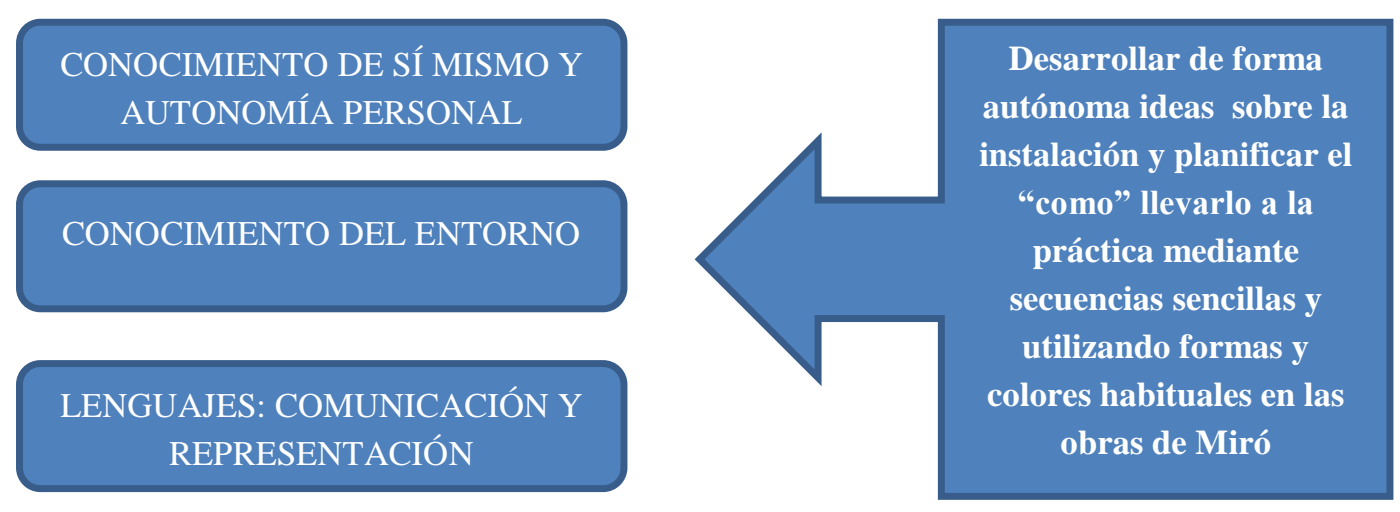

\section{PROYECTO IDDEA: INSTALACIÓN ARTÍSTICA}

Fig. 2

Fuente: Elaboración Propia

Las evaluaciones de los niños ponen de manifiesto que aglutinando los contenidos en ejes más amplios y llevándolos a la práctica mediante intervenciones artísticas es posible el desarrollo de un aprendizaje más profundo y significativo.

En cuanto a la evaluación de satisfacción que realizaron las profesoras de educación infantil, a pesar de que ninguna de ellas había realizado con anterioridad un proyecto de este tipo, se han mostrado muy satisfechas con los resultados, si bien puntualizan que las intervenciones deberían haber durado más tiempo.

Concluyendo, coincidimos con Rabkin y Redmon en que el arte es un facilitador curricular pues acerca la distancia entre el alumno y el aprendizaje. Según estos autores los programas que integran el arte dentro de las asignaturas, obtienen mejores resultados que los aprendizajes curriculares aislados. Generando a su vez beneficios emocionales entre los alumnos tanto en la interacción como en la motivación, se facilita la interdisciplinariedad de las asignaturas a través del arte, los contenidos son más tangibles y la evaluación es más reflexiva (Rabkin y Redmon, 2006). 


\section{Referencias}

Acaso, m.; Megías, C. Art Thinking. Transformar la educación a través de las artes. Barcelona: Paidós, 2017.

Asociación Asire. Asesoramiento, Investigación y Renovación Educativa. 2017. Disponible en: http://www.asire.es/quienes-somos/nuestro-equipo/ Acceso en: 30 ene. 2019

Alonso-Geta, P. M. (2007). Juego y creatividad. Crítica, 947, 25-29.

Delgado, I. (2011). Juego infantil y su metodología. Paraninfo.

Espriú,R.M., “El niño y la creatividad”.Editorial.Trillas.Eduforma.Mexico,2005.

Ley orgánica de ordenación del sistema educativo, BOE núm.106, de 4 de Mayo de 2006.

Ley Orgánica General del Sistema Educativo. BOE núm. 238, de 4 de octubre de 1990.

Ley Orgánica de Mejora de la Calidad Educativa. BOE núm. 295, de 10 de diciembre de 2013,

Rabkin, N., \& Redmond, R,. (2006) The Arts Make a Difference, The Journal of Arts Management,Law, and Society, 36:1, 25-32, DOI: 10.3200/JAML.36.1.25-32

Piaget, J. (1982). La clasificación de los juegos y su evolución a partir de la aparición del lenguaje. Mexico: Fondo de Cultura Económica.

Suárez , M. (2000) Las corrientes pedagógicas contemporáneas y sus implicaciones en las tareas del docente y en el desarrollo curricular. Acción pedagógica No. 1 y 2. Vol. 9 